\title{
Impact of Environmental Changes on Migratory Bird Survival
}

\author{
Sabine Stöcker-Segre and Daniel Weihs \\ Faculty of Aerospace Engineering \& Autonomous Systems Program, Technion, 32000 Haifa, Israel
}

Correspondence should be addressed to Daniel Weihs; dweihs@tx.technion.ac.il

Received 29 July 2013; Revised 10 November 2013; Accepted 9 December 2013; Published 19 February 2014

Academic Editor: Daniel Rubenstein

Copyright (C) 2014 S. Stöcker-Segre and D. Weihs. This is an open access article distributed under the Creative Commons Attribution License, which permits unrestricted use, distribution, and reproduction in any medium, provided the original work is properly cited.

\begin{abstract}
We present a mathematical model that studies and simulates the interconnection between energetic and ecological aspects of bird migration. By comparing model predictions with experimental data, we show that it can be used to assess the impact of changing environmental conditions in breeding, wintering, and stop-over sites on migratory success. We relate in particular to the European white stork (Ciconia ciconia) and its Eastern migration route and discuss questions concerning the timing, stopover, and feeding behavior en route. Opinions concerning the importance of resource availability and resource quality en route are divided. Whereas some studies have shown that storks gain weight in the wintering site, but almost do not feed en route, others stress the importance of the quality of stop-over locations. We address these questions and simulate the development of stork populations for changing environmental conditions. We demonstrate that resource availability and competition for breeding sites are crucial factors determining the timing of spring migration and the length of stop-over periods. Analyzing the robustness of migration strategies with respect to changing environmental conditions, we show that birds will shorten their stay in stop-over places of poor resource availability rather than prolonging it in the attempt to gain time for accumulating fat reserves.
\end{abstract}

\section{Introduction}

Modern technologies, especially satellite tracking, allow for a better understanding of bird migration $[1,2]$. However, in light of global environmental changes new questions are coming up, such as the influence of changing environmental conditions in general and of climate change in particular on long distance migration $[3,4]$. Migration in turn has an influence on the timing of breeding and on reproductive success [5]. This is known as carry-over effects. The understanding of carry-over effects is of importance for conservation measurements under current and predicted global environmental changes [6-8].

The purpose of the present study is to identify the dominant factors and to investigate the impact of changing environmental conditions on the success of migration strategies. We use a model previously developed for bird migration [9] adding parameters relevant to environmental conditions at stop-over locations. We analyze the model's sensitivity with respect to the model's parameters describing migration strategies and environmental conditions. Thus, we study the impact of environmental changes on bird migration and the impact of changing migration strategies on reproductive success through simulations and sensitivity analysis. The results are used to analyze the Eastern route migration of the white stork (Ciconia ciconia), for which data is available from the Movebank [10].

\section{Materials and Methods}

The main equations describing the bird population behavior are the differential equations for population densities of groups of migrating birds (assuming that storks fly in groups at least for some part of the migratory path for safety and energetic reasons) and for biomass, where the biomass divided by the average mass of a bird is defined as the population density. This density is a measure of the birds' fat deposits and available energy. The connection between biomass and population density results from the mass dependency of reproduction and death rates and distinguishes our model from classical logistic growth models. In our model, the male, the female, and the nestling population are treated separately. The latter is treated separately, as nestlings are not actively looking for food items but are fed. 


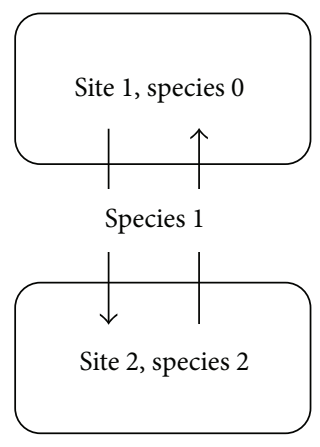

FIGURE 1

Population dynamics are calculated in two sites (see Figure 1):

site 1 is the migrating birds' breeding site;

site 2 is the host site, which is at the same time the breeding site of a nonmigrating species.

Up to three species of birds can be considered.

Species 1 reproduces in site 1 and migrates in winter to site 2 .

Species 0 serves to model competition with species 1 in the breeding site. Species 0 can migrate or not migrate and can be used to study inner-species competition when its characteristics (model parameters) determine migration with a strategy similar to but different from species 1 .

Species 2 is a nonmigrating species staying permanently in the host site (site 2).

A detailed diagram of these concepts appears in Appendix A.

2.1. Population Dynamics and Biomass. We describe changes in population density in both sites considering the following processes:

$$
\begin{aligned}
& \text { births - deaths + immigration (due to migration) } \\
& \text { - emigration (due to migration). }
\end{aligned}
$$

This balance can be formulated as a differential equation:

$$
\begin{aligned}
\frac{d x_{i, j}}{d t}= & x_{i, j} \beta_{i, j}\left(t, m_{i}\right)\left(1-S_{j}\right) \\
& -\delta_{i}\left(m_{i}\right) x_{i, j}-\mu(t) x_{i, j}+\dot{x}_{i, a}(t) .
\end{aligned}
$$

Equation (2) is a logistic equation in which we keep birth and death rates separated, since reproduction happens during the breeding season only, whereas death processes occur variably throughout the year.
In order to describe the change of biomass of the adult population, we consider the following processes:

$$
\begin{aligned}
& \text { feeding - metabolism - laying eggs (for females only) } \\
& \text { - deaths + juveniles reaching adulthood } \\
& \text { - emigration (due to migration) } \\
& \text { + immigration (due to migration) } .
\end{aligned}
$$

Juveniles are considered part of the adult population when they start feeding independently. As previously mentioned, we modeled the growth of nestlings separately.

Considering the processes in the preceding list, the change of biomass appears as follows:

$$
\begin{aligned}
\frac{d b_{i, j}}{d t}= & x_{i, j} \cdot\left(-\beta_{i, j}\left(t, m_{i}\right)\left(1-S_{j}\right) \cdot m_{\mathrm{egg}}+\varphi-v\right) \\
& -\delta_{i}\left(m_{i}\right) b_{i, j}+\dot{x}_{i, j, \mathrm{juv}}(t) m_{\mathrm{juv}} \\
& -\mu(t) b_{i, j}+\dot{b}_{i, a}(t) .
\end{aligned}
$$

Finally, the adult birds' average body mass $m$ is

$$
m=\frac{b_{i, j}(t)}{x_{i, j}(t)} .
$$

2.2. Accumulation of Mass due to Feeding. The gain of body mass due to feeding depends on the quality of the environment, on the activity of the foraging birds, and on the sex [11]. Therefore, we write the gain of feeding (separately for the male and female population) as product:

$$
\varphi=\alpha \cdot r(t) \cdot r_{v} .
$$

The activity $\alpha$ is determined by the duration of daylight, except when birds stop feeding because the net energy gain decreases with increasing foraging efforts due to poor resource availability (further details in Section 2.4). In the stop-over place, we assume that birds will be less active than the fraction of daylight hours allows. The time dependent resource availability $r(t)$ is assumed to be constant in the stop-over places (since birds spend there a relatively short time). We will relate to sex differences, when determining the parameter $r_{v}$ which describes the quality of the environment (Section 2.4).

\subsection{Loss of Mass due to Metabolism. A bird's mass}

(i) decreases at the active metabolic rate $v_{a}$ during the fraction of time spent for foraging $(\alpha)$,

(ii) decreases at the resting metabolic rate at rest $\nu_{r}$ during the rest of the time $(1-\alpha)$.

Hence,

$$
\left.\frac{d m}{d t}\right|_{\text {metabolism }}=-c f \cdot\left[\alpha \cdot v_{a}+(1-\alpha) \cdot v_{r}\right] .
$$


The term in square brackets denotes the metabolic rate $v$ (in Watt) as a linear superposition of active metabolism and metabolism at rest, depending on the time share $\alpha$ of hours of activity:

$$
\nu=\alpha \cdot v_{a}+(1-\alpha) \cdot v_{r}
$$

Next, we calculate metabolic efficiency $(\eta)$ and convert Joules per second (the unit of the metabolic rate) by means of the conversion factor $c f$ to mass units $(\mathrm{kg})$ per time unit (a year).

The metabolic rate as function of a bird's body mass is determined, for active metabolism $\left(\nu_{a}\right)$ and metabolism at rest $\left(\nu_{r}\right)$, respectively, through

$$
v_{a}=k \cdot v_{r}, \quad v_{r}=a_{0} \cdot m^{b} .
$$

The constants $k, a_{0}$, and $b$ are taken from a compilation of results by Norberg [12]:

$$
\begin{gathered}
k=2.5, \\
a_{0}=6.25 \mathrm{~J} / \mathrm{s}, \quad b=0.724 \text { for passerines, } \\
a_{0}=3.79 \mathrm{~J} / \mathrm{s}, \quad b=0.723 \text { for nonpasserines. }
\end{gathered}
$$

2.4. The Energetic Value of the Resource. Since we do not have details of the energetic value of resources in any environment, we determine the energetic value of a resource $r_{v}$ under the assumption that birds will reach their maximum mass with maximum foraging effort and for the maximum of resource availability. As mentioned in the previous sections, a bird's mass

(i) decreases with the active metabolic rate $v_{a}$ during the fraction of time spent foraging $(\alpha)$,

(ii) decreases with the metabolic rate at rest $\nu_{r}$ during the rest of the time $(1-\alpha)$,

(iii) increases with feeding ( $\varphi$, as in (4) and (6)).

Hence,

$$
\frac{d m}{d t}=-c f \cdot\left[\alpha \cdot\left(v_{a}-v_{r}\right)+v_{r}\right]+\alpha \cdot r(t) \cdot r_{v}
$$

and after some manipulation using (9) with the constants $a_{0}, k$, and $b$ as above

$$
\frac{d m}{d t}=-c f \cdot[\alpha \cdot(k-1)+1] \cdot a_{0} \cdot(m / \mathrm{kg})^{b}+\alpha \cdot r(t) \cdot r_{v} .
$$

When the maximum mass is reached, $d m / d t=0$, therefore,

$$
c f \cdot[\alpha \cdot(k-1)+1] \cdot a_{0} \cdot\left(m_{\max } / \mathrm{kg}\right)^{b}=\alpha \cdot r(t) \cdot r_{v},
$$

or

$$
r_{v}=\frac{c f \cdot[\alpha \cdot(k-1)+1] \cdot a_{0} \cdot\left(m_{\max } / \mathrm{kg}\right)^{b}}{\alpha(t) \cdot r(t)}
$$

Resource availability and the activity $\alpha$ change seasonally. We determine $r_{v}$ for the share of active hours $\alpha$ being equal to the share of daylight hours during the longest days of the year and for the maximum of resource availability:

$$
r_{v}=\frac{c f \cdot\left[\alpha_{\max } \cdot(k-1)+1\right] \cdot a_{0} \cdot\left(m_{\max } / \mathrm{kg}\right)^{b}}{\alpha_{\max } \cdot r_{\max }} .
$$

Looking at the units of $r_{v}$, we see that they are the same as those of the change of body mass in (7), since the remaining variables in (15) are dimensionless. Therefore, the dimension of the "value of the resource" is $\mathrm{kg} /$ year: it is the energy in equivalents of body mass a bird of maximum body mass needs throughout a year to sustain its metabolic needs during a period of maximum resource availability and maximum length of daylight hours. Obviously, the value of the resource can be different for the male and the female population (due to different maximum body masses). Therefore, (6) for the accumulation of fat due to feeding allows for sex differences.

2.5. Feeding Periods. The feeding term of (4) and (6) is modified during the various phases of the reproduction period, which are defined by the input data for times: $t_{S}$ (start of egg laying period), $t_{E}$ (duration of egg laying period), $t_{B}$ (duration of breeding out eggs), and $t_{F}$ (length of the feeding period, which starts when chicken hatch and ends when they start feeding autonomously). The female birds' energetic needs raise with conception. Therefore, conception, not egg laying, should be considered as the start of the breeding season. However, the gravidity period is short and can be neglected.

(a) During the egg laying period (from $t=t_{S}$ to $t=t_{S}+$ $t_{E}$ ) male and female birds continue searching for food items and continue feeding regularly. Metabolic rates are active metabolic rates, and food is transformed to energy, body, and egg mass.

(b) While breeding (from $t=t_{S}+t_{E}$ to $t=t_{S}+t_{E}+$ $t_{B}$ ), females and males share foraging and breeding. Therefore, activity and food intake are reduced to half.

(c) While raising juveniles (for the period of $t_{F}$ ), the male and the female move around and share their food with the juveniles. Metabolic rates of both the male and the female are the active metabolic rates but only a part of the males' and females' food is transformed to the adults' population energy and body mass. The rest serves for the energetic needs of juveniles and is transformed to the juveniles' biomass.

(d) At the end of the feeding period adult juveniles actively look for food items and do not need to be fed. Starting with $t=t_{S}+t_{E}+t_{B}+t_{F}$ the feeding terms of (6) apply without any modification to the whole (male and female) population.

2.6. The Impact of Underweight on the Population Size: Mass Dependency of the Reproduction and of the Death Rate. It is obvious that poor resource availability or increased energy requirements during flight reduce a population in size due to the loss of weak individuals. 


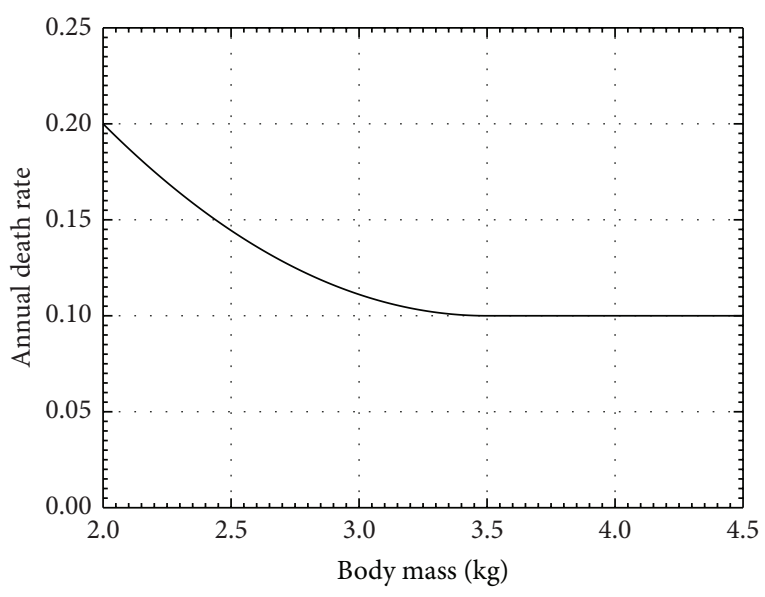

Figure 2: Body mass dependency of the death rate. The example was created for male storks, assuming that their normal body mass is $3.5 \mathrm{~kg}$.

2.6.1. Mass Dependency of the Death Rate. In our model, we assume that the death rate increases with a power law (usually with the second power) in case the birds' average body mass is smaller than the normal mass.

If the average body mass $m$ falls below the normal body mass $m_{n}$, the equation for the body mass dependent death rate $\delta(m)$ reads

$$
\delta(m)=\left(\left(\frac{m-m_{n}}{m_{n}-m_{\min }}\right)^{2}+1\right) \cdot \delta_{0}
$$

with $\delta_{0}$ being the constant death rate for birds not weighing less than the normal weight (Figure 2). Unless otherwise specified, we assumed a normal weight of $3.5 \mathrm{~kg}$ for male and of $3 \mathrm{~kg}$ for female storks.

2.6.2. Mass Dependency of the Reproduction Rate. We assume the reproduction rate to be maximal if the average weight is equal to or larger than the normal weight of birds. Unless otherwise specified, we assume for storks a maximum clutch size of 4 eggs per adult pair and a normal weight of $3.5 \mathrm{~kg}$ for male birds and of $3 \mathrm{~kg}$ for female birds. The clutch size as assumed here is confirmed by field studies [13].

In case the average mass is smaller than the normal mass but larger than the minimum weight required for laying $n$ eggs and raising juveniles, we take the clutch size to shrink linearly:

$$
n=n * \frac{m-m_{b}}{m_{e}-m_{b}} .
$$

Here, $m_{b}$ is the minimum body mass required for breeding and feeding juveniles and $m_{e}$ is equal to $m_{b}$ plus the mass of $n$ (usually 4) eggs. In case the average weight is lower than the minimum weight required for reproduction, the clutch size will be zero (Figure 3).

2.7. Consumption of the Resource. We assume that the function of resource availability $r(t)$ summarizes various kinds of resources such as water and food items in one variable only.

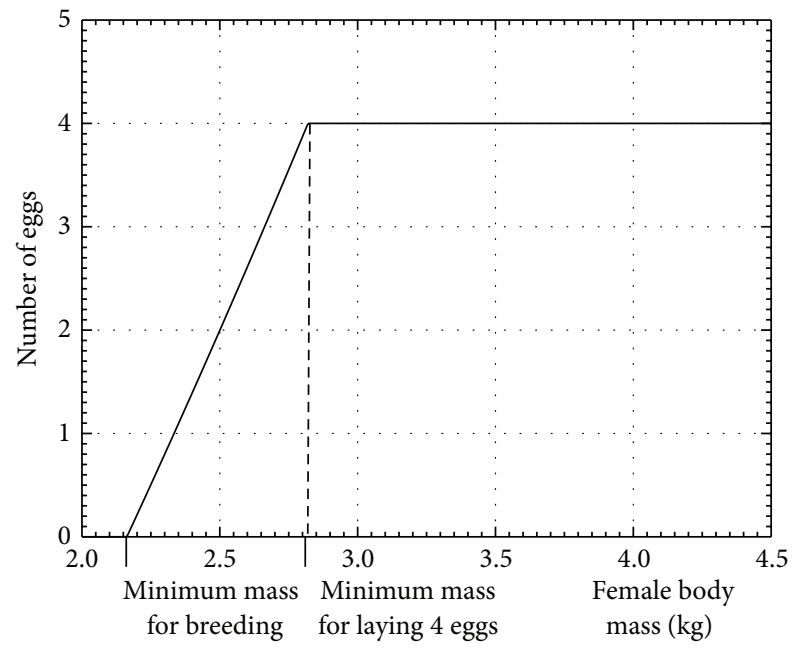

FIGURE 3: Average number of eggs as function of the average female's body mass.

When a population of size $x$ feeds from a resource $r$, this resource decreases in time as

$$
\frac{d r}{d t}=-r(t) \cdot r_{l} \cdot \alpha \cdot x(t)
$$

where $\alpha$ is the birds activity (as before) and $r_{l}$ is the maximum exhaustion rate of the resource. In order to estimate $r_{l}$, we study the extreme case: how quickly does the resource get exhausted by animals of a fully occupied area $(x=1)$ which are foraging constantly during the longest days of the year $\left(\alpha=\alpha_{\max }\right)$ ? With $x=1$ and $\alpha=\alpha_{\max }$, the resource decreases with

$$
\frac{d r}{d t}=-r(t) \cdot r_{l} \cdot \alpha_{\max }
$$

Integration leads to

$$
r(t)=r\left(t_{0}\right) e^{-r_{l} \cdot \alpha_{\max } \cdot t}
$$

The resource is reduced by half after time $t_{1 / 2}=$ $\ln (2) /\left(r_{l} \alpha_{\max }\right)$.

2.8. Energetic Costs of Flight. Birds lose mass during flight due to the consumption of fat as fuel. This loss of mass grows with speed cubed and with the birds mass squared [12] and can be described as

$$
\frac{d m}{d t}=c_{1} v^{3}+c_{2} \frac{1}{v} m^{2}
$$

where $c_{1}$ and $c_{2}$ are aerodynamic constants, depending on the shape of the wings:

$$
\begin{gathered}
c_{1}=\frac{\rho}{2}\left(a S+S_{B}\right), \\
c_{2}=\frac{2 g^{2}}{b \rho S} .
\end{gathered}
$$


Dividing (21) by speed yields body mass consumed per distance $(d m / d s)$. We determine the speed at which maximum range is obtained (maximum range speed) from the derivative of $(d m / d s)$ with respect to the speed $v$ as follows:

$$
\begin{aligned}
& \frac{d m}{d s}=c_{1} v^{2}+c_{2} \frac{1}{v^{2}} m^{2}, \\
& \left.\frac{d}{d v}\left(\frac{d m}{d s}\right)\right|_{v_{\text {max range }}}=0 \\
& \Longleftrightarrow v_{\text {max range }}=\sqrt[4]{\frac{c_{2}}{c_{1}} m^{2} .}
\end{aligned}
$$

Individuals reach their goal after covering a given distance (input parameter dist) between the two sites. The distance $R$ traversed at time $t$ is calculated as

$$
R_{t_{d}}(t)=\int_{t_{d}}^{t} v\left(y\left(\tau, t_{d}\right)\right) d \tau
$$

We now assume that birds fly a certain fraction of a day (6 to 10 hours). The number of flight hours is an input parameter. We calculate the maximum range speed for flapping flight based on wing-specific data as in (23). Storks, however, cover long distances gliding and soaring, and measured values of velocities en route differ by about $20-30 \%$ from our calculations of the maximum range speed (observed values between 35 and $40 \mathrm{~km} / \mathrm{h}$ as opposed to calculated maximum range velocities during flapping flight between 45 and $50 \mathrm{~km} / \mathrm{h}$ ). Our model allows for two additional factors: an energy-saving-factor for adapting (calculated) energy costs of flapping flight to energy costs of gliding and soaring and a second factor that allows adjusting calculated maximum range speeds for flapping flight to observed velocities of soaring and gliding.

2.9. Stopovers. During long migration, birds stop over to rest and to feed. The stop-over time shifts the arrival time, which has an impact on the competition for breeding sites and on the timing of breeding. In our model, birds stop over once, when half of the distance between the two sites is covered. During stopover, birds feed and (re)accumulate mass. Due to exhaustion, activity might be reduced compared to the birds' activity in the host and in the breeding site. The length of the stop-over period and the birds' activity in the stop-over place are variables whose impact on the success of a specific migration strategy we are investigating.

Since the period of time which birds spend in the stop-over place is relatively short, we assume the resource availability, the daylight hours, and the birds' activity to be constant. The assumption of constant resource availability might be oversimplifying. Indeed, seasonal changes in the resource availability of the stop-over site do probably affect the timing of stopovers $[14,15]$.

\section{Results}

3.1. Model Results and Field Data. The travelling distance from the breeding grounds in North Germany or Poland to Northeastern Africa, where many birds stop over, is about $4600 \mathrm{~km}$ [16]. In the following, we will compare the travelling time predicted by the model with values mentioned in the literature and values resulting from Movebank data (maintained by [10]). According to Berthold, the ca. $4600 \mathrm{~km}$ distance to latitude $18^{\circ} \mathrm{N}$ is covered in an average of 18-19 days by both young and adult storks. Van den Bossche et al. [17] report similar values, writing that birds need only 14 to 24 days to fly from the breeding area to Sudan, but more than twice as much to cover the same distance in spring. This large difference between spring and autumn migration is caused by more and longer stopovers in spring and shorter daily distances crossed on days with bad weather conditions.

We extracted from Movebank a dataset of 13 Argos transmitters placed on white storks (the name of the dataset on Movebank is "MPIO White Stork Argos") and wrote out the dates when these storks passed the latitude of $52^{\circ}$ North and the latitude of $18^{\circ} \mathrm{N}$ (to which Berthold refers). From these dates, we calculated the traveling time in days, its average value, and standard deviation. Datasets were excluded when no data were transmitted in a vicinity of $1^{\circ}$ to the $18^{\circ}$ mark or when no data were transmitted between the latitudes of $51.8^{\circ}$ and of $54^{\circ}$ North (the regions where the traced birds bred). Of some birds, data of successive years are available (in these cases, the tag number is not repeated in successive rows of the table), and one bird was excluded since it migrated on the Western route.

In Table 1, we calculated the traveling time in the days of autumn migration resulting from Movebank data.

In Table 2, we calculated the traveling time in the days of spring migration resulting from Movebank data.

As previously described in the literature [17], traveling times of spring migration are about 2 weeks longer than the traveling time of autumn migration.

Table 3 shows the traveling time in days according to our model for birds of various sizes. In order to receive these results, we reduced the calculated maximum speed for flapping flight by a factor of 0.7 , since storks are used to soaring and gliding over long distances, and assumed 8 hours of flight per day. Traveling times were calculated with the following model parameters (see (21)-(23)): $S_{b}$ (total drag area of the body) $=0.01 \mathrm{~m}^{2}$, air density $\rho=1.2 \mathrm{~kg} / \mathrm{m}^{3}, a$ (depends on the shape of the wing profile, data according to $\mathrm{v}$. Mises $)=0.006, b$ (depends on the aspect ratio, data according to $\mathrm{v}$. Mises) $=15$.

Comparing literature values and traveling times derived from Movebank data with traveling times predicted by our model, it can be seen that without further assumptions (such as stop-over breaks) our model predicts the duration of autumn migration correctly. In order to describe the duration of spring migration correctly, longer periods of rest need to be added. This observation is in accordance with the predictions of our model according to which additional breaks during spring migration enhance reproductive success.

\subsection{Analytical Solutions}

3.2.1. Population Dynamics. With the simplifying assumption of constant (rather than weight dependent) birth and 
TABLE 1: Traveling time of autumn migration in days as derived from Movebank data.

\begin{tabular}{|c|c|c|c|c|}
\hline Tag number & $\begin{array}{l}\text { Approximate location before } \\
\text { leaving for autumn migration }\end{array}$ & $\begin{array}{l}\text { Date of start } \\
\text { of migration }\end{array}$ & $\begin{array}{c}\text { Date when passing } \\
18^{\circ} \text { North } \\
\end{array}$ & $\begin{array}{l}\text { Number of } \\
\text { days passed }\end{array}$ \\
\hline $14543 B$ & $52.1^{\circ}$ North & $25 / 08 / 1997$ & $18 / 09 / 1997$ & 24 \\
\hline \multirow{3}{*}{ 40534B } & $52.1^{\circ}$ North & $16 / 08 / 2004$ & 01/09/2004 & 16 \\
\hline & $52.1^{\circ}$ North & $26 / 08 / 2005$ & $11 / 09 / 2005$ & 16 \\
\hline & $52.1^{\circ}$ North & $15 / 08 / 2006$ & 09/09/2006 & 25 \\
\hline 77195A & $52.1^{\circ}$ North & $11 / 09 / 2009$ & 01/10/2009 & 20 \\
\hline $91397 \mathrm{~A}$ & $53.9^{\circ}$ North & $15 / 08 / 2009$ & $30 / 08 / 2009$ & 15 \\
\hline \multirow{2}{*}{$93411 \mathrm{~A}$} & $51.8^{\circ}$ North & $21 / 08 / 2009$ & $11 / 09 / 2009$ & 21 \\
\hline & $51.8^{\circ}$ North & $12 / 08 / 2010$ & $02 / 09 / 2010$ & 21 \\
\hline $93412 \mathrm{~A}$ & $53.3^{\circ}$ North & $18 / 08 / 2009$ & 08/09/2009 & 21 \\
\hline Average of travelling time & & & & 19.89 \\
\hline Standard deviation from average & & & & 3.35 \\
\hline
\end{tabular}

TABLE 2: Travelling time in days of spring migration as derived from Movebank data.

\begin{tabular}{|c|c|c|c|c|}
\hline Tag number & $\begin{array}{c}\text { Date when passing } \\
18^{\circ} \text { North line } \\
\end{array}$ & $\begin{array}{l}\text { Date of arrival to } \\
\text { breeding site }\end{array}$ & $\begin{array}{c}\text { Location of } \\
\text { breeding site }\end{array}$ & $\begin{array}{l}\text { Number of } \\
\text { days passed }\end{array}$ \\
\hline $14544 \mathrm{D}$ & $27 / 03 / 1999$ & $01 / 05 / 1999$ & $52.1^{\circ}$ North & 35 \\
\hline \multirow{2}{*}{ 40534B } & $23 / 03 / 2005$ & $25 / 04 / 2005$ & $52.1^{\circ}$ North & 33 \\
\hline & $22 / 03 / 2006$ & $21 / 04 / 2006$ & $52.1^{\circ}$ North & 30 \\
\hline $54988 \mathrm{~A}$ & $12 / 03 / 2011$ & 05/04/2011 & $54.2^{\circ}$ North & 24 \\
\hline \multirow{2}{*}{ 77195A } & $29 / 03 / 2010$ & 01/05/2010 & $52.1^{\circ}$ North & 33 \\
\hline & $18 / 02 / 2011$ & $04 / 04 / 2011$ & $52.1^{\circ}$ North & 45 \\
\hline 91399A & $18 / 02 / 2010$ & $26 / 03 / 2010$ & $54.2^{\circ}$ North & 36 \\
\hline \multirow{2}{*}{$93411 \mathrm{~A}$} & $05 / 03 / 2010$ & $04 / 04 / 2010$ & $51.8^{\circ}$ North & 30 \\
\hline & $28 / 02 / 2011$ & $04 / 04 / 2011$ & $51.8^{\circ}$ North & 35 \\
\hline Average of travel time & & & & 33.44 \\
\hline Standard deviation & & & & 5.68 \\
\hline
\end{tabular}

death rates, the equations describing population dynamics (without migration) can be solved analytically.

During breeding season, the population increases by

$$
\text { growth }=x \beta(1-x) \text {, }
$$

where $\beta$ is the net reproduction rate (reduced by the breeding success):

$$
\begin{aligned}
\beta & =\frac{\text { average number of eggs }}{\text { individual }} \cdot \text { breeding success } \\
& =\frac{\text { brood size }}{2} \cdot \text { breeding success. }
\end{aligned}
$$

The latter equation, in which we equate the number of eggs per adult pair with brood size, holds when neglecting nonbreeding birds.

Throughout the year population density decreases at a constant per capita death rate $\delta$. Consider

$$
\frac{d x}{d t}=-\delta x
$$

During one year $(t=1)$ a population of original size $x$ shrinks according to

$$
x(t)=x e^{-\delta \cdot t}=x e^{-\delta}
$$

that is, the losses during one year sum up to

$$
\text { loss }=x-x e^{-\delta}=x\left(1-e^{-\delta}\right) \text {. }
$$

Population dynamics are of period 1 when the losses due to death are equal to the growth due to reproduction. Requiring that the growth term of (25) equals the loss term of (29) yields

$$
x \cdot\left(1-e^{-\delta \cdot t}\right)=x \cdot \beta \cdot(1-x) .
$$

For $x \neq 0$ and $t=1$ (confronting growth and losses of one year), this is equivalent to

$$
\begin{aligned}
x= & 1-\frac{1-e^{-\delta}}{\beta} \approx 1-\frac{\delta}{\beta}+\frac{\delta^{2}}{2 \beta} \\
& -\cdots(\text { in second order approximation) }
\end{aligned}
$$


TABLE 3: Traveling times for birds of various sizes as predicted by our model.

\begin{tabular}{lccc}
\hline $\begin{array}{l}\text { Body mass } \\
\text { (in } \mathrm{kg} \text { ) }\end{array}$ & $\begin{array}{c}\text { Wingspan } \mathrm{i} \\
\text { (in } \mathrm{m} \text { ) }\end{array}$ & $\begin{array}{c}\text { Maximum range } \\
\text { velocity in } \mathrm{km} / \mathrm{h}\end{array}$ & $\begin{array}{c}\text { Number of days necessary } \\
\text { to overcome dist }=4600 \mathrm{~km}\end{array}$ \\
\hline 2.5 & 2 & 37.62698105 & 21.83083916 \\
2.5 & 2.2 & 35.35709422 & 23.23235519 \\
3 & 2 & 41.21829258 & 19.92873843 \\
3 & 2.2 & 38.73175614 & 21.20814167 \\
3.5 & 2 & 44.52084438 & 18.4504266 \\
3.5 & 2.2 & 41.83507806 & 19.63492384 \\
4 & 2 & 47.59478464 & 17.25879375 \\
4 & 2.2 & 44.72357967 & 18.36678946 \\
\hline
\end{tabular}

To check the stability of this solution and of the trivial solution $(x=0)$ we derive the net change of $x$ with respect to $x$ as follows:

$$
\begin{aligned}
\frac{\partial}{\partial x}\left[x \beta(1-x)-\left(1-e^{-\delta}\right) x\right] & =\beta(1-2 x)-\left(1-e^{-\delta}\right) \\
& \approx \beta(1-2 x)-\delta+\delta^{2} .
\end{aligned}
$$

As long as $\beta$ is larger than $\delta$, this expression is larger than zero for $x=0$, that is, for the trivial solution, whereas it is negative for the nonzero solution $x \approx 1-\delta / \beta$, which is therefore stable. Accordingly, we observe in our simulations that results do not depend on initial values of population densities.

3.2.2. Example of a Theoretically Calculated Value. We ran simulations for various parameter sets. According to one of the most recent publications, which refers to a white stork population in Western Poland [13], the average number of eggs per nest was 3.81, mean hatching success was $76 \%$, and breeding success averaged at 0.8 . Total breeding success (referring to the number of fully fledged juveniles to eggs laid) is the product of the latter two parameters. With $\beta=3.81 / 2$ (eggs/parent bird) $\cdot 0.76$ (hatching success) $\cdot 0.80$ (breeding success $)=1.16$ and $\delta=0.1$, the above calculated equilibrium value of population dynamics is $x=0.91$. This indicates an upper limit for population densities that can be reached in our simulations. Since reproduction rates are weight dependent and often smaller than $\beta$, and since death rates increase for birds of low body mass, simulations show very often smaller population densities. Population densities which we report in the following sections are for males or females only; the entire population is therefore about twice as large. The degree to which population densities in simulations differ from the here calculated upper limit sheds light on the question to which degree the conditions and migration strategies that we checked are favorable.

We state that the logistic equation [18-20], on which our model is based, in its continuous form has one stable attracting fix-point. The discrete logistic equation shows periodic solutions and a bifurcation diagram for increasing reproduction rates [21]. Though our model is semidiscrete (reproduction occurs once a year only, death processes throughout the year), we did not find evidence of chaotic behavior in the parameter regions which we checked. Reproduction rates in our model are very small when compared to critical values of the bifurcation diagram of the logistic equation.

3.2.3. Resource Availability. The question wether a certain environment is favorable for wintering, breeding, or stopping over depends among others on resource availability. In a first, simplifying approach, we describe the complexity of resource availability with one parameter only. This allows us to calculate critical values, which will later on help to run simulations in critical parameter regions, to check the system's response to environmental stress, and to estimate that way the impact of environmental changes.

Birds consume energy when foraging, during migration and for reproduction. Whereas the last two events occur seasonally, birds consume throughout the year energy for foraging. In the following, we will analyze the net energy gain.

According to (6) and (7) the net energy gain is equal to

$$
r(t) r_{v} \cdot \alpha(t)-c f\left(\alpha v_{a}+(1-\alpha) \nu_{r}\right) \text {. }
$$

Deriving with respect to $\alpha$ yields

$$
r(t) r_{v}-c f\left(v_{a}-v_{r}\right)
$$

where $v_{a}$ and $v_{r}$ are the active metabolic rate and the metabolic rate at rest, respectively, and depend on the bird's body mass.

This expression is larger than zero only if

$$
r(t)>\frac{c f\left(v_{a}-v_{r}\right)}{r_{v}} .
$$

We assume that in case resource availability falls below this critical value, birds stop feeding (e.g., during winter).

Figure 4 shows the gain of feeding, the foraging costs, and the net feeding gain as a function of the activity $\alpha$ for a case of very poor resource availability. Since the net energy gain is negative and falls with increasing $\alpha$, birds will stop feeding in such a case.

It has, however, to be noted that even in cases of sufficient resource availability and an increasing net energy gain function, net energy gain can still be negative, unless birds spend enough time for feeding. Figure 5 shows a case of medium resource availability, where birds need to forage 


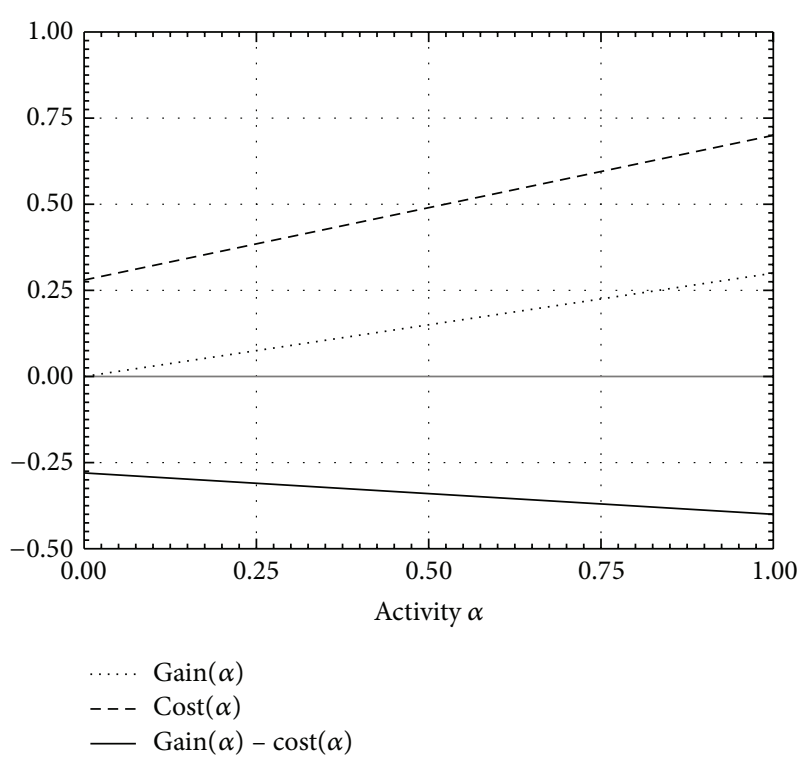

FIGURE 4: Net energy gain as a function of a bird's activity (number of active hours divided by $24 \mathrm{~h}$ ) for poor resource availability. The values on the $y$-axis are normalized (divided by the maximum active metabolic rate of a foraging bird of maximum mass).

at least $55 \%$ of the time for gaining more energy than investing in foraging. These considerations are important when discussing the value of stop-over places, knowing that birds will arrive exhausted and will therefore be less active.

Requiring that the net energy gain as in (33) be larger than zero and resolving it with respect to $\alpha$ yield

$$
\alpha>\frac{c f v_{r}}{r r_{v}-c f\left(v_{a}-v_{r}\right)} .
$$

From this equation, it can be seen that the minimum activity required decreases with increasing resource availability $r$ and with an increasing value of the resource $r_{v}$. Though we assumed in a first approach that all resources in all sites (stopover sites, breeding sites, and wintering sites) are of the same value, this is probably not the case and the minimum required activity might be smaller than estimated when resources are particularly valuable.

Figure 6 shows the minimum activity necessary for gaining more energy than investing in foraging, as a function of resource availability for a normal weight female of $3 \mathrm{~kg}$ body mass. When resource availability falls below 0.6 (i.e., below $60 \%$ of its maximum) positive net energy intake is not possible. In such a case, strong birds would rather skip stopover places than losing time and energy.

Summarizing, there are two levels of resource availability. On a first (medium) level, birds need to spend a minimum time foraging for gaining more energy than investing. Such a situation might be critical in stop-over places where birds are exhausted from migration and therefore less active. On a second level of even poorer resource availability, the net energy gain will decrease with increasing foraging effort. In such a case birds will probably stop feeding. This might be the case for nonmigrating birds during winter.

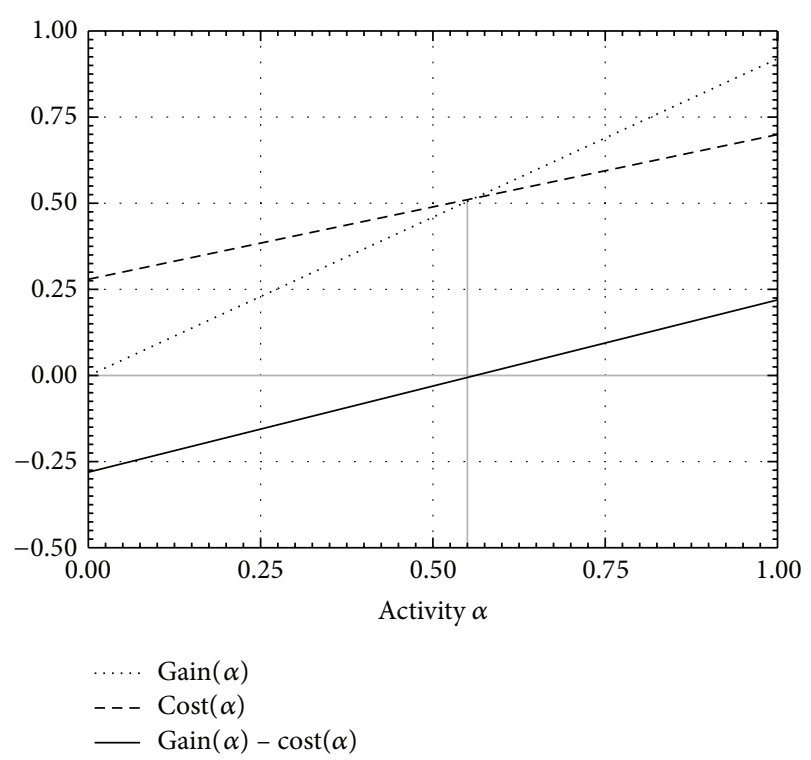

Figure 5: Net energy gain as a function of a bird's activity for medium resource availability. Birds need to forage at least $55 \%$ of the time for gaining more energy than investing. The $y$-axis is normalized as in Figure 4.

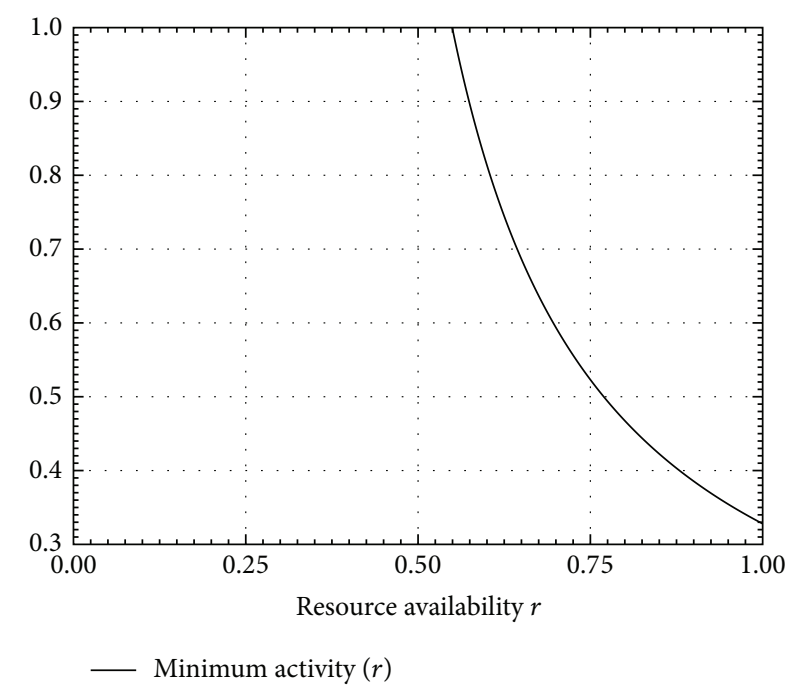

FIGURE 6: Minimum activity necessary for gaining more energy than investing in foraging as a function of resource availability for a normal weight female stork of $3 \mathrm{~kg}$ body mass. Values on the $y$ axis are fractions of a day and therefore dimensionless.

In Section 4 we search for the best migration strategy in cases when resource availability in the stop-over places requires minimum activity. We do, of course, not pretend that birds "know" how to choose the best strategy but that groups of birds which accidentally follow the better pattern will be fitter and reproduce better.

In the preceding, we checked the net energy gain in stop-over places, assuming that birds are exhausted from migration and active for a fixed amount of reduced hours. We now assume that birds are active during daylight hours, 


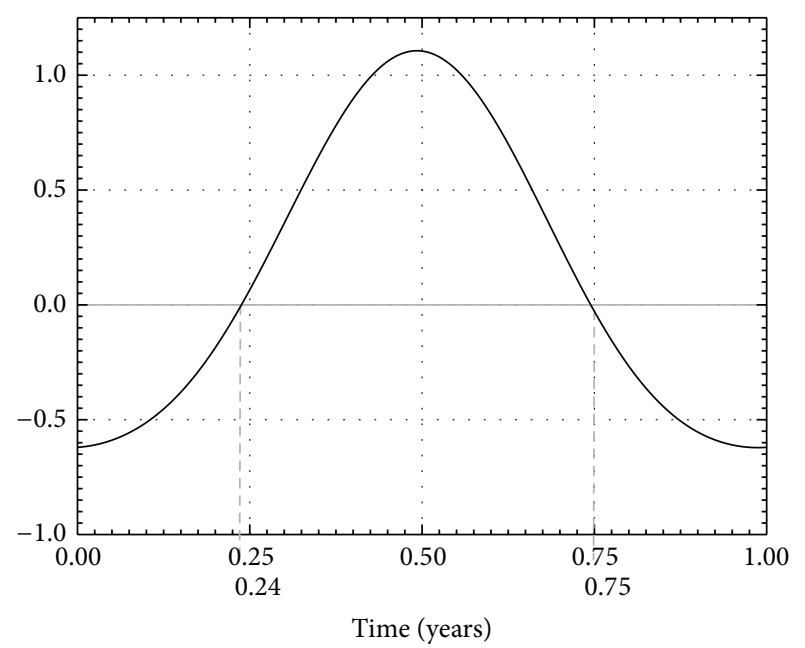

— Net energy gain

FIGURE 7: Net energy gain for a bird of minimum body mass as a function of time, assuming that birds are active during daylight hours. On the vertical axes: change of body mass per day in percent of body mass.

as it is approximately the case in the breeding site, and check during which period net energy gain is positive (activity depends probably not only on daylight hours, but on the birds' energetic needs, too). In the following, we check the model's reliability assuming that birds are active during day and rest during night.

Net energy gain is a function of time, since resource availability and daylight hours change with season. The following figures were produced assuming that resource availability oscillates sinusoidally between 0.3 and 0.9 and the fraction of daylight hours between 0.35 and 0.65 (see the exact functions in Appendix B). A year starts when day light hours are at their minimum (i.e., $t=0$ is 10 days before the 1st of January). Since metabolic rates are a function of body mass, we show one graph for a bird of minimum body mass $(2 \mathrm{~kg})$ and a second one for a female bird of normal body mass $(3 \mathrm{~kg})$.

In the time interval during which net energy gain is positive, the extra energy can be used for reproduction and for the accumulation of fat (possibly as fat reserves for migration). The first graph (for a bird of minimum body mass) is relevant to the return to the breeding site (the end of spring migration): since birds will arrive with a low body mass and cannot lose further body mass, they should not arrive earlier than the date at which the net energy gain starts to be positive (in Figure 6-0.24, which corresponds to the second half of March). Figure 7 indicates the date of departure for autumn migration. In order to have fat reserves for migration, birds will not start later than the date at which normal weight birds would start to lose body mass (in Figure $7-0.68$, which corresponds to the last week of August). The time interval of positive net energy gain depends, of course, on the exact choice of the functions for resource availability and daylight hours and serves to verify the model.

\section{Simulation Results}

We examined various parameter sets and investigated the questions listed below, taking population density in the end of the breeding season as an indicator for the fitness of the group of birds under the conditions to be checked. The simulation programs and input data files (containing model parameters) can be obtained from the authors. When discussing simulation results, we use expressions like "the best departure date" and "optimum stop-over period" for simplicity. As already stated, we do, of course, not pretend that birds "know" how to choose the best strategy but that groups of birds which accidentally follow the better pattern will be fitter and reproduce better.

(1) What is the best date to leave for (spring and autumn) migration?

(2) To what degree does the length of stop-over periods have an impact on reproductive success?

(3) What is the impact of competition on timing?

(4) When should breeding start with respect to the date of return from spring migration?

(5) To which degree do the preceding results change, when resource availability in the stop-over sites changes?

4.1. Timing of Spring Migration. We assumed that resources are abundant and slightly oscillating in the wintering site (see Appendix B for the equations of the seasonally varying resource availability and amount of daylight hours), and the resources are poor during winter in the breeding site and abundant in the stop-over site ( $r=1$, constant). We then simulated migration with the previously described model and checked what should be the best date for spring departure and the optimum length of the stop-over period. Subsequently, we checked the best date for autumn departure and the optimum length of the stop-over period during autumn.

As a first example, we assume that in the stop-over site birds will be active and foraging during $40 \%$ of the time, that is, for an average of 9.6 hours each day. Without competition (simulating one group of birds only) a large range of departure dates and stop-over periods is possible. A migrating group of birds can sustain itself with no significant changes in size as long as the departure date is between 0.1 and 0.3 . Migratory success increases with the length of the stop-over period; see Figure 9. For extreme late spring departures $\left(t_{d}>\right.$ 0.3 ) the stop-over time needs to be reduced in order to guarantee early arrival in the breeding site. The migrating birds' population size reaches its maximum (0.32) when spring migration starts at 0.18 (corresponding to the last week of February) and when birds stop over for a period of 0.2 during spring migration (corresponding to 2 months and 12 days).

According to this result, birds would do best stopping over for more than two months-much longer than what has been observed in field studies. The reason is that foraging $40 \%$ of the time in a rich stop-over place is advantageous from an energetic point of view. In reality, birds will probably be exhausted from migration, will spend less time for feeding 
and therefore gain less energy in the stop-over place. In addition, they have to face competition for the better breeding sites. Thus, they will probably stop over for a shorter period. In the following simulation, one group of birds leaves at 0.18 and stops over for a period of 0.2 (i.e., according to the optimum values of the preceding study). For the second group of birds, we scan through a range of departure dates and lengths of stop-over periods and check reproductive success in the end of the breeding season for each parameter set. Due to competition with the first group of birds, the optimum departure date is anticipated to be 0.11 (the beginning of February) and the optimum stop-over length is shortened to 0.17 (two months).

Results change drastically when assuming that the birds' activity in the stop-over place will be reduced to $30 \%$ of the time (due to exhaustion). Under this assumption, a group of migrating birds will be able to sustain a maximum density of 0.19 when leaving at 0.31 (the beginning of April) and not stopping over at all. When the net energy gain in a stop-over place is too poor (either because of poor resource availability or because of reduced activity) the stop-over site will be frequented for a much shorter period or not at all, and birds would do best to leave the wintering site as late as possible.

4.2. Timing of Autumn Migration. Autumn migration is different in the sense that after arriving to the wintering site there will be no competition for breeding sites.

Taking the spring departure time to be 0.18 (the last week of February) with a stop-over period of 0.1 (corresponding to 5 weeks), we checked a range of departure dates for autumn migration and a range of stop-over periods during autumn migration.

The best time to leave for autumn migration is shortly after juveniles are fully fledged. Afterwards, resources start being poor in the breeding site, and birds will not be able to accumulate fat reserves for migration. Figure 10 shows the population density in the end of the breeding season as function of the date of leaving for autumn migration (on the axis pointing to the right) and as function of the length of the stop-over period (on the axis pointing to the back). Migratory success decreases when autumn departure is delayed, but in the range from 0.02 (corresponding to one week) to 0.2 (corresponding to two months and a half) migratory success does almost not depend on the length of the stop-over period. The exact stop-over length is not critical, since resource availability in the stop-over site and in the wintering site are comparable, and since there is no particular advantage of arriving early (as opposed to the breeding site). These results do almost not change when we take competition into account. The optimum stop-over time gets slightly reduced from 0.1 to 0.07 (corresponding to 25 days), due to competition for (anyway abundant) resources in the wintering site. The optimum departure date does not change.

4.3. When Breeding Should Start. Checking a range of delays between the return from spring migration and the start of breeding (defined by the first egg), population densities reached maximum values for a delay of 0.08 years which roughly corresponds to one month. This is in accordance with observational values and in correspondence with our analysis of resource availability according to which birds should not arrive earlier than $t=0.24$ (with respect to the shortest day of the year). Taking into account that juveniles should be raised when resource availability is at its maximum, the time span between the earliest possible arrival date and the maximum of resource availability does not allow larger delays of the breeding season.

4.4. Dependency of the Stop-Over Period on Resource Availability. Stopovers are a trade-off between gaining energy and arriving later to the breeding site. To determine the optimum stop-over time we checked the development of groups of birds under various assumptions of resource availability in the stop-over place.

First, we checked the optimum stop-over time (optimum in the sense of guaranteeing maximum reproductive success) as function of increasing resource availability in the stop-over place, assuming that birds will be active during $40 \%$ of the time (corresponding to 9.6 hours/day). As long as there is no net energy gain, birds will do better to stop over as briefly as possible. As soon as resource availability allows a net energy gain, the length of stop-over periods increases drastically.

In Figure 11, we show observed stop-over times in the beginning of the inclining part, when the (normalized) value of resource availability is about 0.8 and the stop-over time is shorter than 0.04 (corresponding to $0.04 * 365=14.6$ days). Here, resource availability is equal to the lower values of resource availability in the wintering site (where resource availability varies between 0.8 and 1 ). When resources are abundant in the stop-over place (parameter values larger than 0.85 ), our model predicts strangely long optimum stopover periods of up to one-fifth of a year (corresponding to more than two months). This trend is not necessarily a contradiction to observations, since it has been reported that young birds do not always return to the breeding site [17]. For a similar species, the oriental white stork (Ciconia boyciana), it has indeed been reported that a small subpopulation turned stop-over places to breeding sites [22]. Thus, stop-over sites can be visited, at least by individual birds, for significantly more than two weeks.

Analysis of the net energy gain in a given environment and simulations shows that birds, as long as they are strong enough, will skip poor stop-over places (possibly looking for alternatives) and prolong their stay in extremely favorable environments. The latter prediction is in accordance with observations and even taken to the extreme in cases of storks that started wintering in Spain rather than only stopping over [23]. There is no reason to assume that birds will prolong their stay in poor stop-over sites attempting to gain time for putting on weight. Such a strategy would not only be a waste of energy, but of time, too, bearing the additional risk of subsequently encountering a poor choice of breeding sites.

Summarizing, as a direct effect of decreasing resource availability in the stop-over places (as caused by human change of the landscape), birds will arrive weaker in the breeding site and produce less offspring. An indirect effect of decreasing resource availability is that birds will spend less and less time in the respective stop-over place and even 
totally skip this place. As a direct effect of increasing resource availability (as caused by global warming or rubbish points), birds will produce more offspring in a single year. As an indirect effect, they will prevail more in the place, delay their return, and might even turn the stop-over site to a semipermanent site.

\section{Discussion}

The optimal timing of migration, including stopovers, is a trade-off between arriving fit for reproduction and arriving early for occupying the better sites [24-27]. In the previous section, we evaluated a number of migration strategies for one and for two groups of storks competing for space (assuming that storks fly in groups at least for some part of the migratory path). Seeing that the success of a certain migration strategy is strongly influenced by the presence of other individuals that migrate with a slightly different strategy (especially in terms of timing), it might be interesting to study the development of a population that is distributed over a number of individuals or groups of birds, each following its own migration pattern (in terms of leaving for spring migration and stopping over). Which birds will perform best? How many birds can coexist? And how is the distribution over various migration strategies affected by changing resource availabilities?

Competition manifests itself as a crucial factor with a strong impact. Our equations of population dynamics are based on the logistic equation where competition for space appears in form of a linear reduction factor: $(1-S)$, where $S$ is the space being occupied by all coexisting species $\left(S=\sum_{j=1}^{2} x_{j}\right)$. Knowing that storks tend to return to their nests and that that way their breeding success increases [28], a nonlinear competition function $f(1-S)$ depending, for example, on the $n$th root of $(1-S)$ might be more appropriate: some part of the population does not encounter any competition $(f(1-S) \rightarrow 1$ for small $S)$, whereas birds that cannot return to any nest (because their nests got destroyed or because they are breeding for the first time) face an even stronger competition for the remaining breeding sites $(f(1-S) \rightarrow 0$ for $S \rightarrow 1)$.

Our simulations suggest that birds that return stronger but later to the breeding site will reproduce better due to increased resource availability in the stop-over places. In fact, anticipated returns to the breeding site have been reported. As such, white storks return about 10 days earlier from Africa to Western Poland than they did 100 years ago [13]. We do, however, not know the exact reason for these anticipated returns. It might be the decreased (instead of increased) resource availability in the stop-over site and possibly the influence of further environmental factors such as weather conditions en route.

Our model predicts prolonged stays in the stop-over sites when resources are abundant. In light of this prediction the definition of "stop-over site" should be reconsidered. We suggest three types of sites in addition to the breeding and the wintering site.

(i) The first is "rest sites", where birds stay usually for one night and for not more than 48 hours mainly with the purpose to rest. Since birds are exhausted, they will hardly feed in these places.

(ii) The second is "stop-over sites" where birds stay about two weeks to rest and to feed. These places are mainly frequented during spring migration (and the reason for longer spring than autumn migrations).

(iii) We suggest to add "semi-permanent sites" to the list where birds stop for more than two weeks. Individual birds, looking for niches, might explore these sites for reproduction.

Using results from sensitivity analysis, we are planning to further reduce the model presented here to its essential parts. In view of the huge availability of tracking data, we hope that we will be able to integrate a more realistic description of de facto existing migration routes into the model, to identify factors that particularly endanger migrating stork populations, and to point out windows where protection measurements will be particularly helpful.

So far, we estimated only roughly the energy savings of gliding and soaring with respect to flapping flight, as well as the ratio of time spent in soaring and gliding to time spent flapping. We hope to validate our model with ACC data from the Movebank (triaxial acceleration data transmitted by GPS tracked animals). We are planning to analyze these data with Fourier transformation tools which will hopefully allow us to estimate flapping rates. We are planning to confront quantitative results concerning flight performance with meteorological data which are available through the NCEP (National Centers for Environmental Prediction) and the ECMWF (European Center for Medium-Range Weather Forecast).

\section{Appendices}

\section{A. Diagram of the Model}

See Figure 12.

\section{B. Daylight Hours and Resource Availability}

Figures 7 and 8 were produced with the following functions for the share of daylight hours $\alpha(t)$ and resource availability $r(t)$ :

$$
\alpha(t)=\frac{\left(\alpha_{\max }-\alpha_{\min }\right)}{2} \cdot \sin \left(2 \pi\left(t-\frac{1}{4}\right)\right)+\frac{\alpha_{\max }+\alpha_{\min }}{2}
$$

with $\alpha_{\min }=0.35$ and $\alpha_{\max }=0.65$

$$
r(t)=\frac{\left(r_{\max }-r_{\min }\right)}{2} \cdot \sin \left(2 \pi\left(t-\frac{1}{4}-\theta\right)\right)+\frac{r_{\max }+r_{\min }}{2}
$$

with $r_{\min }=0.3$ and $r_{\max }=0.9$.

Here, $\theta$ is the phase shift between the seasonal oscillations of day length and the seasonal oscillations of resource availability. We chose $\theta=1 / 6$, since the maximum of resource availability usually "lags" about two months behind the maximum of day length. 


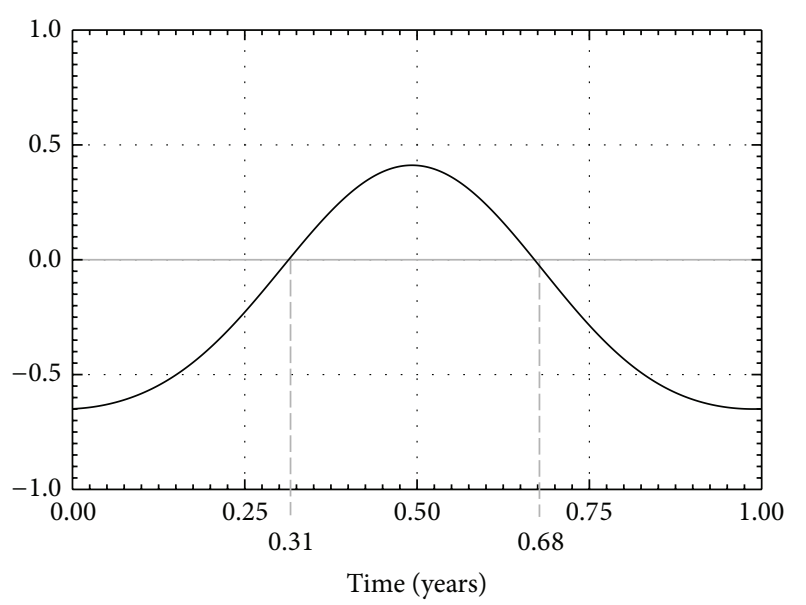

— Net energy gain

FIGURE 8: Net energy gain for a female bird of normal body mass, assuming that birds are active during daylight hours. On the vertical axes: change of body mass per day in percent of body mass.

The same functions were used for the simulations starting from Section 4 . The above values are extreme values in the breeding site. Extreme values in the wintering site are $\alpha_{\min }=$ $0.45, \alpha_{\max }=0.55, r_{\min }=0.8$, and $r_{\max }=1.0$. The maxima in the wintering site are shifted by $\Phi=0.5$ (half a year).

\section{Nomenclature}

\section{In Alphabetical Order, Greek Letters after Latin Letters}

$\dot{b}_{i, a}(t)$ : Rate of increase of biomass due to arriving species (returning from migration) in $\mathrm{kg} /$ year

$b_{i, j}(t)$ : Biomass of species $i$ in site $j$ at time $t$ in $\mathrm{kg}$

$c$ : The mass of fat containing 1 Joule of energy: $c=(38939 \mathrm{~J} / \mathrm{g})^{-1}=$

$2.6 \cdot 10^{-8} \mathrm{~s}^{2} / \mathrm{m}^{2}$

$c f$ : Conversion factor for the conversion of energy required to body mass consumed including metabolic efficiency, $c f=1 / \eta \cdot c \cdot$ year, in $(\mathrm{kg} / \mathrm{J}) \cdot(\mathrm{s} /$ year $)$

$i$ : Index indicating the number of the species

$j: \quad$ Index indicating the number of the site ( $j=1$ : breeding site, $j=2$ : wintering site)

$m_{i}$ : The average body mass of a bird of species $i$ in $\mathrm{kg}, m_{i}=b_{i, j}(t) / x_{i, j}(t)$

$m_{b}$ : The minimum body mass in kg required for breeding and feeding juveniles

$m_{e}: \quad m_{b}$ plus the mass of $n$ (usually 4) eggs, in $\mathrm{kg}$

$m_{\text {egg }}:$ Average mass of an egg in $\mathrm{kg}$

$m_{\text {juv }}$ : Average body mass of juvenile birds in $\mathrm{kg}$

$m_{\min }$ : When the birds' average body mass falls below $m_{\min }$, the population will become extinct, in $\mathrm{kg}$

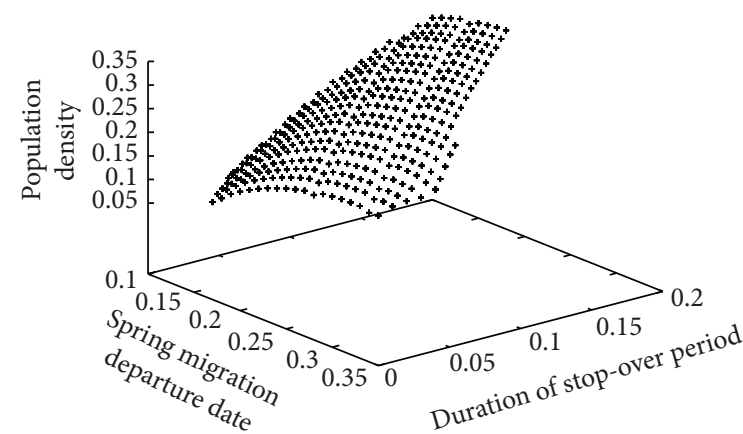

FIGURE 9: Dependence of the population density at the end of the breeding period on the date of departure for spring migration and on the length of the spring stop-over period resulting from simulations. Excluding competition, extreme long stopovers are advantageous. All times are with respect to a year of length 1 , starting at the shortest day of the year.

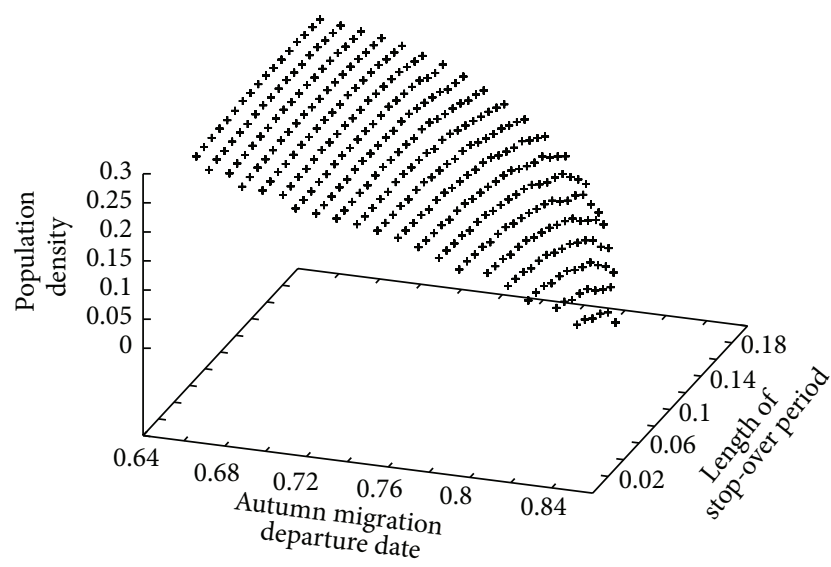

FIGURE 10: Dependence of the population density at the end of the breeding period on the date of departure for autumn migration and on the length of the autumn stop-over period resulting from simulations. Due to shrinking resources in the breeding site, the best departure date is right after the end of the breeding season. The length of the stop-over period is not critical. All times are with respect to a year of length 1 , starting at the shortest day of the year.

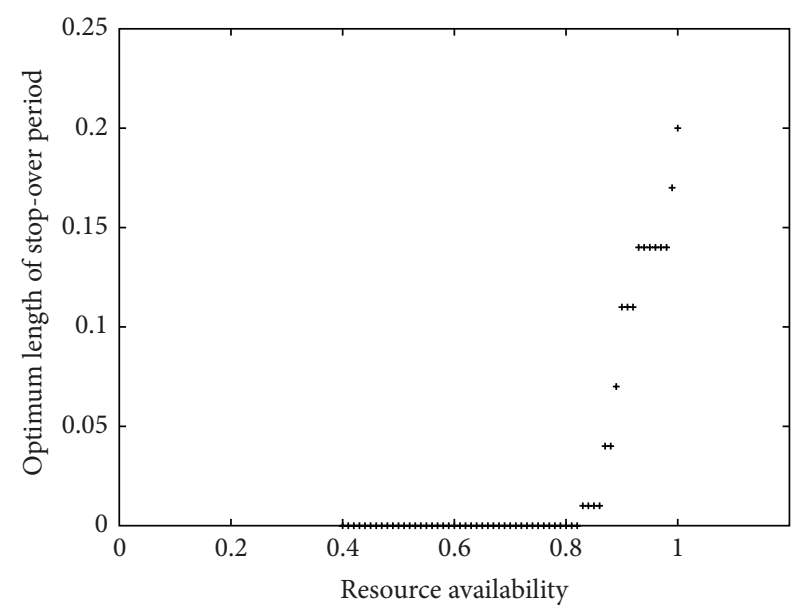

FIGURE 11: Dependence of the optimum stop-over time on resource availability. Resource availability is normalized with respect to its maximum. Time on the vertical axis is normalized with respect to a year. 


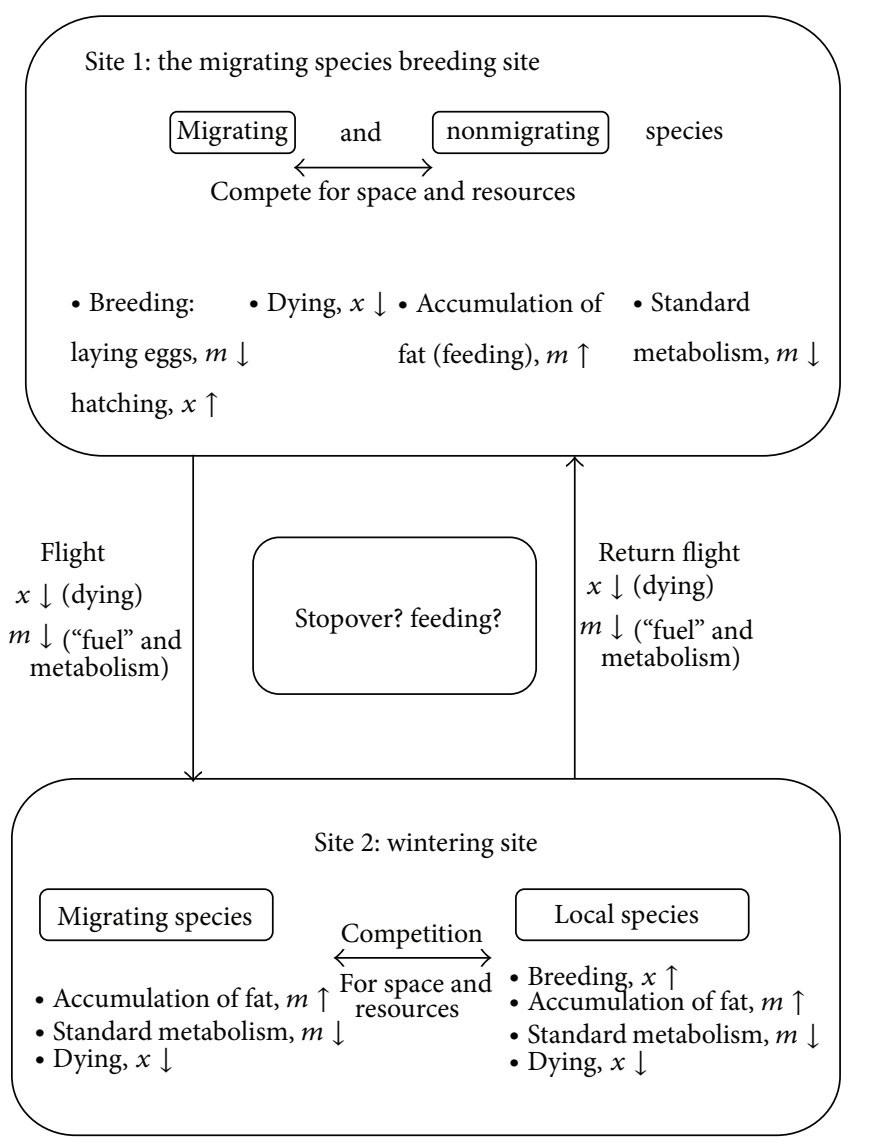

FIGURE 12: Detailed diagram of the migration model. All changes in population densities $x$ and the birds' average mass $m$ that as described by differential equations are listed. The upward-pointing and downward-pointing arrows denote increases and decreases, respectively; they are qualitative rather than quantitative.

$m_{n}$ : Normal body mass of a bird in $\mathrm{kg}$. If the average birds' body mass falls below the normal body mass, the death rate will increase

$n: \quad$ Number of eggs

$r(t)$ : Time dependent resource availability, dimensionless, $0<r(t)<1$

$r_{\text {max }}:$ Resource availability at maximum (during summer), dimensionless

$r_{\min }:$ Resource availability at minimum (during winter), dimensionless

$r_{l}$ : The maximum exhaustion rate of the resource; the larger $r_{l}$, the faster the resource will be exhausted, in year ${ }^{-1}$

$r_{v}: \quad$ Energetic value of the resource for the bird species under consideration in $\mathrm{kg} / \mathrm{year}$

$S_{j}: \quad$ Area share being occupied by all species living in site $j\left(\sum_{i} x_{i, j}\right)$, dimensionless

$t$ : $\quad$ Time

$t_{B}$ : Length of breeding period as fraction of a year, dimensionless
$t_{E}: \quad$ Duration of the egg-laying period dimensionless

$t_{F}$ : Duration of feeding period, dimensionless

$t_{S}$ : Start of breeding period, more exactly, the fraction of a year that has passed since the minimum of resource availability $(t=0)$ when the first egg is laid, dimensionless

$t_{1 / 2}$ : Half period time of the resource in years, $t_{1 / 2}=\ln (2) /\left(r_{l} \cdot \alpha_{\max }\right)$

$x_{i, a}(t)$ : Population share arriving (returning) per time interval $d t$ and at time $t$ after (from) migration, in units of year ${ }^{-1}$, dimensionless

$x_{i, j}(t): \quad$ Area share occupied by species $i$ in site $j$ at time $t$ (briefly, population density) or number of animals divided by the maximum number of animals the area can sustain (which is equivalent), dimensionless

$x_{i, j, \mathrm{juv}}(t)$ : Population density of fledging juveniles at time $t$, dimensionless

$y: \quad \quad$ Number of seconds per year (31536000)

$\alpha: \quad$ Fraction of a time unit spent for foraging, dimensionless.

$\alpha_{\max }: \quad$ Share of daylight hours during the longest day of the year, dimensionless

$\alpha_{\min }$ : $\quad$ Share of daylight hours during the shortest day of the year, dimensionless

$\beta_{i, j}\left(t, m_{i}\right)$ : Annual reproduction rate of species $i$ in site $j$; a function of the birds' average body mass $m$ and nonzero in the beginning of the breeding season only, in units of year ${ }^{-1}$

$\delta_{0}$ : $\quad$ Basic death rate, applies throughout the year, in units of year $^{-1}$

$\delta_{i, j}: \quad$ Annual death rate of species $i$ in site $j$ (population share lost per year), in units of year $^{-1}$

$\delta(m): \quad$ Mass dependency of the death rate

$\eta: \quad$ Metabolic efficiency, dimensionless

$\mu$ : $\quad$ Migration rate (population share leaving for migration per time unit), in units of year $^{-1}$

$v: \quad$ Metabolic rate as a function of the bird's mass $(m)$ and activity $(\alpha)$ in Watt $(\mathrm{J} / \mathrm{s})$

$v_{r}: \quad$ Metabolic rate at rest, $v_{r}=a_{0} \cdot m^{b}$ where $a_{0}$ and $b$ are species-dependent constants; in Watt $(\mathrm{J} / \mathrm{s})$

$v_{a}: \quad$ Active metabolic rate in Watt, $v_{a}=2.5 v_{r}$

$\varphi$ : $\quad$ Rate of accumulating mass due to feeding in $\mathrm{kg} /$ year, $\varphi=\alpha \cdot r(t) \cdot r_{v}$

$\Theta$ : $\quad$ Phase shift between the maxima of day light hours and resource availability

$\Phi: \quad$ Phase shift between the maxima of day light hours in the wintering and in the breeding site. 


\section{Variables of Section 2.8}

a: $\quad$ Dimensionless constant which depends mainly on the shape of the wing profile and which determines among other variables the constant $c_{1}$ below

b: $\quad$ Dimensionless constant which depends mainly on the aspect ratio of the wing and which determines among other variables the constant $c_{2}$ below

$c_{1}, c_{2}$ : Aerodynamical constants, depending on the shape of the wings and determining among other variables the amount of energy consumed during flight, $c_{1}$ in $\mathrm{kg} / \mathrm{m}, c_{2}$ in $\mathrm{m}^{3} /\left(\mathrm{kg} \cdot \mathrm{s}^{4}\right)$

dist: $\quad$ Distance in $\mathrm{km}$ to be covered during migration

$g: \quad \quad$ Gravitational acceleration $\left(9.81 \mathrm{~m} / \mathrm{s}^{2}\right)$

$R(t)$ : Distance in $\mathrm{km}$ covered during migration at time $t$

$S: \quad$ Wing area in $\mathrm{m}^{2}$

$S_{B}: \quad$ Total drag area of the bird in $\mathrm{m}^{2}$

$t_{d}$ : Departure time, more exactly, the fraction of a year that has passed since the minimum of resource availability $(t=0)$ when birds leave for migration, dimensionless.

$v: \quad$ Migration speed in $\mathrm{m} / \mathrm{s}$

$v_{\text {max range }}$ Maximum range speed in $\mathrm{m} / \mathrm{s}$

$v\left(y\left(\tau, t_{d}\right)\right)$ : Speed at time $\tau$ of group of birds $y$ that had left at departure time $t_{d}$

$\rho: \quad$ Air density in $\mathrm{kg} / \mathrm{m}^{3}$.

\section{Conflict of Interests}

The authors declare that there is no conflict of interests regarding the publication of this paper.

\section{Acknowledgments}

This study was carried out as part of the DIP project "Understanding lifetime tracks and fitness of long-distance avian migrants" (Professor Ran Nathan, project coordinator). The authors thank Mr. Michael Kaatz for the data and Dr. Nir Sapir for useful advice. They extend their thanks to an anonymous reviewer for useful comments.

\section{References}

[1] M. R. Fuller, W. S. Seegar, and P. W. Howey, "The use of satellite systems for the study of bird migration," Israel Journal of Zoology, vol. 41, no. 3, pp. 243-252, 1995.

[2] P. Berthold, Bird Migration: A General Survey, Oxford University Press, New York, NY, USA, 2nd edition, 2001, Translated by H. Günther Bauer and V. Westhead.

[3] C. Both, S. Bouwhuis, C. M. Lessells, and M. E. Visser, "Climate change and population declines in a long-distance migratory bird," Nature, vol. 441, no. 1, pp. 81-83, 2006.
[4] C. E. Studds and P. P. Marra, "Reconsidering the role of precipitation and food availability in relation to the effect of photoperiod on spring departure of a migratory bird," Proceedings of the Royal Society B, vol. 279, no. 1726, pp. 17-18, 2011.

[5] A. P. Møller, D. Rubolini, and E. Lehikoinen, "Populations of migratory bird species that did not show a phenological response to climate change are declining," Proceedings of the National Academy of Sciences of the United States of America, vol. 105, no. 42, pp. 16195-16200, 2008.

[6] F. Bairlein and M. Schaub, "Ringing and the study of mechanisms of migration," Ringing \& Migration, vol. 24, no. 3, pp. 162$168,2009$.

[7] P. Tryjanowski and T. H. Sparks, "The relationship between phenological traits and brood size of the white stork Ciconia ciconia in western Poland," Acta Oecologica, vol. 33, no. 2, pp. 203-206, 2008.

[8] M. E. Visser, "Keeping up with a warming world; assessing the rate of adaptation to climate change," Proceedings of the Royal Society B, vol. 275, no. 1635, pp. 649-659, 2008.

[9] S. Stöcker and D. Weihs, "Bird migration-an energy-based analysis of costs and benefits," IMA Journal of Mathemathics Applied in Medicine \& Biology, vol. 15, no. 1, pp. 65-85, 1998.

[10] Max Planck Institute for Ornithology, North Carolina Museum of Natural Sciences, and The University of Constanz, "Movebank for animal tracking data," https://www.movebank.org.

[11] Z. Kwieciñski and P. Tryjanowski, "Differences between sexes in digestive efficiency of the white stork Ciconia ciconia under experimental conditions," Folia Biologica, vol. 57, no. 3-4, pp. 193-198, 2009.

[12] U. M. Norberg, Vertebrate Flight, Springer, Berlin, Germany, 1990.

[13] J. Z. Kosicki, "Reproductive success of the white stork Ciconia ciconia population in intensively cultivated framlands in western Poland," Ardeola, vol. 75, no. 2, pp. 243-255, 2010.

[14] M. Schaub, W. Kania, and U. Köppen, "Variation of primary production during winter induces synchrony in survival rates in migratory white storks Ciconia ciconia," Journal of Animal Ecology, vol. 74, no. 4, pp. 656-666, 2005.

[15] B.-E. Sæther, V. Grøtan, P. Tryjanowski, C. Barbraud, S. Engen, and M. Fulin, "Climate and spatio-temporal variation in the population dynamics of a long distance migrant, the white stork," Journal of Animal Ecology, vol. 75, no. 1, pp. 80-90, 2006.

[16] P. Berthold, W. van den Bosch, W. Fiedler et al., "Der zug des weigstorchs (Ciconia ciconia): eine besondere zugform auf grund neuer ergebnisse," Journal Für Ornithologie, vol. 142, pp. 73-92, 2001.

[17] W. Van den Bossche, P. Berthold, M. Kaatz, E. Nowak, and U. Querner, Eastern European White Stork Populations: Migration Studies and Elaboration of Conservation Measures, vol. 66, Bundesamt für Naturschutz, Konstantinstr, Germany, 2002.

[18] W. C. Allee, Principles of Animal Ecology, Saunders, Philadelphia, Pa, USA, 1949.

[19] C. J. Krebs, Ecology: The Experimental Analysis of Distribution and Abundance, Harper \& Row, New York, NY, USA, 1972.

[20] A. L. Jensen, "Comparison of logistic equations for population growth," Biometrics, vol. 31, no. 4, pp. 853-862, 1975.

[21] R. M. May, "Simple mathematical models with very complicated dynamics," Nature, vol. 261, no. 5560, pp. 459-467, 1976.

[22] L. Zhou, W. Xue, S. Zhu, K. Shan, and J. Chen, "Foraging habitat use of oriental white stork (Ciconia boyciana) recently breeding in China," Zoological Science, vol. 30, no. 7, pp. 559-564, 2013. 
[23] F. S. Tortosa, M. Manez, and M. Barcell, "Wintering white storks (Ciconia ciconia) in south west Spain in the years 1991 and 1992," Die Vogelwarte, vol. 38, no. 1, pp. 41-45, 1995.

[24] L. Von Haartman, "The evolution of resident versus migratory habit in birds. Some considerations," Ornis Fennica, vol. 45, pp. $1-7,1968$.

[25] S. Cramp and K.E.L. Simmons, Eds., The Birds of the Western Palearctic, vol. 1, Oxford University Press, Oxford, UK, 1977.

[26] H. Dallinga and M. Schoenmakers, "Population changes of the White Stork Ciconia ciconia since the 1850s in relation to food resources," in Proceedings of the 1st International Stork Conservation Symposium, G. Rheinwald, J. Ogden, and H. Schulz, Eds., Schriftenreihe des Dachverbandes Deutscher Avifaunisten, pp. 231-262, Braunschweig, Germany, 1989.

[27] P. D. Goriup and H. Schulz, "Conservation management of the white stork," in Conserving Migratory Birds, T. Salathé, Ed., vol. 12, p. 393, International Council for Bird Preservation, Cambridge, UK, 1991.

[28] P. Vergara, J. I. Aguirre, J. A. Fargallo, and J. A. Dávila, "Nestsite fidelity and breeding success in white stork Ciconia ciconia," IBIS International Journal of Avian Science, vol. 148, no. 4, pp. 672-677, 2006. 

